\title{
Study On The Responsiveness of A Novel \\ Pyrimidine-BODIPY Probe For Rapid Identification of Different Amino Acids
}

\section{Feng Jin}

Anhui University of Science and Technology College of Medicine

Tingyu Shao

Jiangsu University

Guofan Jin ( $\square$ organicboron@ujs.edu.cn )

Jiangsu University https://orcid.org/0000-0001-6585-1496

\section{Research Article}

Keywords: Pyrimidine-BODIPY probe, amino acid, tyrosine, rapid identification, short-time identification

Posted Date: May 10th, 2021

DOI: https://doi.org/10.21203/rs.3.rs-331516/v1

License: (c) (i) This work is licensed under a Creative Commons Attribution 4.0 International License.

Read Full License 


\section{Abstract}

Rapid identification of different amino acid responses is of great importance in the field of biomedicine. Through the combination of the drug intermediate pyrimidine with the fluorophore BODIPY, a new type of high-efficiency fluorescent probe for rapid identification of different amino acids was prepared. In terms of photophysical properties, the UV absorption and fluorescence emission of the mercapto groups were observed under the conditions of different hydroperoxide equivalents and different solvents, and the maximum values were in the range of 534-538 nm and 554-560 nm. When different amino acids were added, the UV absorption and fluorescence emission ranges were $538 \sim 540 \mathrm{~nm}$ and $560 \sim 564 \mathrm{~nm}$. Finally, the identification sensitivity of amino acids with different equivalents under different oxidant conditions was quickly detected by fluorescence cuvette. Among them, the identification response to tyrosine was the most obvious.

\section{Introduction}

Amino acids are one of the many bioactive macromolecules for the construction of biological organisms, and they are the basic materials for the construction of cells and the repair of tissues. Amino acids are used by the body to make antibody proteins that fight bacterial [1,2] and viral infections [3, 4], to make hemoglobin that carries oxygen [5-7], and to make enzymes and hormones that maintain and regulate metabolism [8-11]. Amino acids are the main substances for the production of sperm [12-14] and egg cells $[15,16]$ and the indispensable prerequisite for the synthesis of neurotransmitters $[17,18]$. Amino acids, which power the body $[19,20]$ and brain [21, 22], are essential to all life. Twenty kinds of basic amino acids are known, including tyrosine, lysine, threonine, leucine, isoleucine, valine, methionine, tryptophan, phenylalanine, and other amino acids. Since amino acids are closely related to major diseases and human pathological mechanisms, their balance and adequate supply are the basic prerequisites for human health. The lack of any supply of an amino acid, will affect the normal immune system and other functions of the play, make the person is in a state of sub-health, are more vulnerable to disease. Therefore, how to quickly detect the responsiveness of different amino acids is still a hot field.

Recently, many researchers have devoted themselves to the research and development of many new highefficiency amino acid probes in this field. Such as, Raines et al. and Lei et al. reported using diazo compounds to esterify the carboxylic acid groups in proteins [23] and Waldmann et al. developed Woodward's reagent $\mathrm{K}$ for covalent protein labeling at glutamic acids [24]. Shen et al. reported design of a chiral aldehyde probe D-BPBR with bromine isotope, and carried out a series of chiral amino acid analysis studies combined with high performance liquid chromatography/mass spectrometry. Ma et al. and Et et al. reported that $2 \mathrm{H}$-azirine was generated by using sodium azide and iodine chloride, and then 3-phenyl$2 \mathrm{H}$-azrine was synthesized using traditional methods to label glutamate and aspartic acid [25].

Although these probes are of great significance in amino acid labeling, they lack one part in the efficient and rapid detection of conventional amino acids, namely, short-time identification. Based on this design idea, we synthesized a simple and efficient pyrimidine-BODIPY (PyBODIPY) fluorescent probe. 


\section{Experimental Section}

\section{Reagents and instrumentation}

All reagents were purchased commercially and further purified when used. All the reactions involved were monitored by thin-layer chromatography (TLC) and analyzed with ultraviolet lamps at 254 and $365 \mathrm{~nm}$. Products were separated and purified by column chromatography (200-300 mesh silica gel). NMR were recorded by Bruker avance II instrument in deuterium chloroform (400 MHz for ${ }^{1} \mathrm{H}$ and $100 \mathrm{MHz}$ for ${ }^{13} \mathrm{C}$ ). Chemical shifts are reported in ppm, versus internal tetramethylsilane (TMS) as a standard. The mass spectrum was obtained on a Thermo LXQ by liquid chromatgraphy-ion trap mass spectrometry. Absorption spectra were recorded with a UV-2550 spectrophotometer. The fluorescence emission spectra were measured by Shimazu RF-5301PCS fluorescence spectrophotometer with excitation wavelength of $500 \mathrm{~nm}$. The molecular weight by MS-ESI (Jeol LTD JMS-HX 110/110A) was performed.

\section{Synthesis}

ethyl (Z)-4-((2-((1-(difluoroboraneyl)-5-((4-ethyl-3,5-dimethyl-2H-pyrrol-2-ylidene)(phenyl) methyl)-1H-pyrrol2-yl)amino)ethyl)amino)-2-(methylthio)pyrimidine-5-carboxylate.

(Z)-N1-(1-(difluoroboraneyl)-5-((4-ethyl-3,5-dimethyl-2H-pyrrol-2-ylidene)(phenyl)methyl)-1 H-pyrrol-2$\mathrm{yl}$ )ethane-1,2-diamine (BODIPY- $\mathrm{NH}_{2}{ }^{\text {ref }}, 0.23 \mathrm{~g}, 0.6 \mathrm{mmol}$ ) was dissolved in dichloromethane $(8 \mathrm{~mL})$, ethyl 4-chloro-2-(methylthio)pyrimidine-5-carboxylate $(0.15 \mathrm{~g}, 0.6 \mathrm{mmol})$ and triethylamine $(80 \mu \mathrm{L}, 1.2 \mathrm{mmol})$ were added. The reaction was stopped after magnetic stirring at room temperature for $5 \mathrm{~h}$. Red compound (PyBODIPY, $0.21 \mathrm{~g}, 63 \%$ ) was isolated by column chromatography (petroleum ether: EtOAc $=$ 2:1). ${ }^{1} \mathrm{H}-\mathrm{NMR}:\left(400 \mathrm{MHz}, \mathrm{CDCl}_{3}, \mathrm{ppm}\right): \delta 8.68(\mathrm{~s}, 1 \mathrm{H}), 8.47(\mathrm{~s}, 1 \mathrm{H}), 7.45-7.28(\mathrm{~m}, 5 \mathrm{H}), 6.48(\mathrm{~d}, \mathrm{~J}=4.0 \mathrm{~Hz}, 1 \mathrm{H})$, 6.15(s, 1H), $6.02(\mathrm{~d}, J=4.0 \mathrm{~Hz}, 4 \mathrm{H}), 4.36-4.30(\mathrm{~m}, 2 \mathrm{H}), 3.87-3.82(\mathrm{~m}, 2 \mathrm{H}), 3.62-3.57(\mathrm{~m}, 2 \mathrm{H}), 2.56(\mathrm{~s}, 3 \mathrm{H})$, 2.49(s, 3H), 2.37-2.31 (m, 2H), 1.39(s, 3H), $1.37(\mathrm{t}, \mathrm{J}=6.0 \mathrm{~Hz}, 3 \mathrm{H}), 1.03(\mathrm{t}, \mathrm{J}=4.0 \mathrm{~Hz}, 3 \mathrm{H}) ;{ }^{13} \mathrm{C} \mathrm{NMR}(100 \mathrm{MHz}$, $\left.\mathrm{CDCl}_{3}\right): \delta(\mathrm{ppm})=176.41,166.75,160.59,159.62,158.49,145.76,135.28,133.88,132.94,132.87,132.25$, $130.23,129.67,128.55,128.41,128.02,105.58,101.33,61.0,43.85,40.19,17.17,14.93,14.22,14.18$, 11.94, 11.58. ITMS (ESI) calcd for $\mathrm{C}_{29} \mathrm{H}_{33} \mathrm{BF}_{2} \mathrm{~N}_{6} \mathrm{O}_{2} \mathrm{~S}[\mathrm{M}+\mathrm{H}]^{+} \mathrm{m} / \mathrm{z} 578.5$; found 579.2.

\section{Detect of different amino acid method}

Seven empty cuvettes were selected to add $5 \mu \mathrm{g} / \mathrm{mL}$ PyBODIPY at one time, followed by 1.0 2.0 hydrogen peroxide with different equivalents. After the completion of the reaction for 5 minutes, 1.0 equivalents of different amino acids were added again for 5 minutes. Different solvents were selected for UV absorption and fluorescence emission detection in each step [26-31].

\section{Result And Discussion}

\section{Design}


The design concept of amino acid fluorescent probe is that considering the error of detection results caused by the toxicity of the probe itself, pyrimidine [32-34], which is widely used in the drug field, is selected as the intermediate of targeting action to introduce the fluorescent group BODIPY [35]. This design not only greatly reduces the toxicity problem of the probe, but also has certain drug activity in the overall structure. The best of both worlds. (Fig-1 and Scheme-1).

The mercapto group in the pyrimidine structure is easily oxidized by hydrogen peroxide, while the sulfonyl group sandwiched between two nitrogen atoms is extremely unstable and easily attacked by nucleophilic groups to form an amino acid-pyrimidine-BODIPY structure. Due to the changes of the overall structure, different amino acid compounds produce different color changes under the irradiation of $365 \mathrm{~nm}$ wavelength, so as to detect the identification of different amino acids (Fig-2).

In order to observe the changes of pyrimidine-bodipy in different solvents and hydrogen peroxide solutions with different equivalents, continuous detection was conducted from 1.0 to 2.0. As shown in Table 3, the curve changes in methanol and tetrahydrofuran solutions are almost overlapped without any change. Although the other four solvents fluctuated slightly up and down the curve, the overall difference remained at the same level. It can be concluded from the results that the influence of sulfonyl group on the ultraviolet spectrum of the whole structure is negligible.

Table 1

Photophysical characteristic of PyBODIPY in different solvent

\begin{tabular}{|lllllll|}
\hline Solvent & EtOAc & $\mathrm{CH}_{2} \mathrm{Cl}_{2}$ & DMSO & $\mathrm{MeOH}$ & EtOH & THF \\
\hline $\begin{array}{l}\lambda_{\mathrm{abs}} \\
\text { max }\end{array}$ & 534 & 538 & 536 & 534 & 535 & 536 \\
$\lambda_{\mathrm{em}}$ & 554 & 555 & 560 & 554 & 554 & 556 \\
$\max$, & & & & & & \\
\hline
\end{tabular}

From Fig. 4 that the results of the overall fluorescence spectrum are similar to those of the ultraviolet spectrum described above, without significant changes. However, the fluorescence intensity changes in DMSO, which is different from that in other polar solvents, indicating that the probe has a good response effect in DMSO. Table-1 shows the data processing of UV spectrum and fluorescence spectrum in Figure 3 and 4 above. As can be seen, the overall value does not change much, and only DMSO shows spectral properties that are different from other solvents.

Compared with Fig. 3 above, there are obvious curve changes in Fig. 5. Each corresponding amino acid showed a strong reactivity with PyBODIPY, indicating that they had produced a responsive effect between them. Although the fluctuation of the overall curve is not very big, but there is a difference in the intensity of absorption. In particular, tyrosine exhibited strong responsiveness under 1.0 equivalent condition, which was different from other amino acids. 
Table 2

Photophysical properties of compound 1 with amino acids in DMSO solution

\begin{tabular}{|lcccccc|}
\hline Solvent & Gly & His & Tyr & Trp & Phe & Cys \\
\hline $\begin{array}{l}\lambda_{\text {abs }} \\
\text { max }\end{array}$ & 540 & 538 & 539 & 538 & 538 & 539 \\
\hline $\begin{array}{l}\lambda_{\mathrm{em}} \\
\text { max }\end{array}$ & 560 & 560 & 564 & 562 & 560 & 561 \\
\hline
\end{tabular}

Compared with Fig. 4, the curves of histidine, tryptophan and phenylalanine showed little change, but the overall fluorescence intensity was all improved. The fluorescence emission intensity of glycine, tyrosine and cysteine varies obviously (Fig-6). Although the range of change is not very large, but can indicate that each other has a responsive effect. In fact, it is not difficult to see from Table 2 that the data changes in Table 1 obviously increase the intensity trend.

By comparing the fluorescence identification of six different amino acids, it can be observed that the color of PyBODIPY is bright transparent pink under sunlight. When adding different equivalents of hydrogen peroxide from 1.0 to 2.0 , the color of the blank sample is yellow-green, and all the others are bright yellow. The indicates that oxidation reactions of hydrogen peroxide with the mercapto group of PyBODIPY, resulting in the change of color. On the other hand, the same amino acid does not change much in color and maintains the same fluorescence regardless of the excess of hydrogen peroxide. When different amino acids such as tryptophan, glycine, histidine, phenylalanine, and cysteine are added, the color changes are not obvious, although some color differences occur. The response of tyrosine was the most prominent, and the overall color changed to green, which was equal to the effect of blank sample.

\section{Conclusion}

In this study, a new type of PyBODIPY fluorescent probe for rapid and efficient identification of different amino acids was described. It was characterized by easy preparation, strong practicability and short response time. Among them, the identification response to tyrosine was the most obvious. This probe is suitable for research in the field of major diseases or rapid diagnosis. Convenience and fastness are the highlight of this study, which will provide an important reference for the future development of more fluorescent probes in the same field.

\section{Declarations}

\section{Acknowledgment}

We would like to thank the scientific research foundation of Jiangsu University (Grant No. 5501290005) for the financial supports. 
JF and STY were responsible for the collation and characterization of experimental data. JGF responsible for writing and reviewing papers.

\section{Funding}

The scientific research foundation of Jiangsu University (Grant No. 5501290005)

\section{Data Availability}

All data generated or analysed during this study are included in this published article and its supplementary information files.

\section{Declaration of competing interest}

The authors declare no competing financial interest.

\section{References}

1. Shaper M, Hollingshead SK, Benjamin WH, Briles DE (2004) PspA protects Streptococcus pneumoniae from killing by apolactoferrin, and antibody to PspA enhances killing of pneumococci by apolactoferrin. Infect Immun 72:5031-5040

2. Kumar S, Tomar AK, Yadav S (2014) Heparin binding carboxypeptidase E protein exhibits antibacterial activity in human semen. Int J Biol Macromol 64:319-327

3. Belanger $\mathrm{H}$, Fleysh N, Cox S, Yusibov V (200) Human respiratory syncytial virus vaccine antigen produced in plants. FASEB J 14: 2323-2328

4. DeDiego ML, Chiem K, Topham DJ (2018) Directed selection of amino acid changes in the influenza hemagglutinin and neuraminidase affecting protein antigenicity. Vaccine 36:6383-6392

5. Wu G, Yan SM (2008) Building quantitative relationship between changed sequence and changed oxygen affinity in human hemoglobin beta-chain. Protein Pept Lett 15:341-345

6. Wiwanitkit V (2008) Single amino acid substitution in important hemoglobinopathies does not disturb molecular function and biological process. Int J Nanomed 3:225-227

7. Thom CS, Dickson CF, Gell DA, Weiss MJ (2013) Hemoglobin Variants: Biochemical Properties and Clinical Correlates. Cold Spring Harbor Perspect Med 3:a011858

8. Liu ZQ, Barrett EJ (2002) Human protein metabolism: its measurement and regulation. Am J Physiol Endocrinol Metab 283:E1105-E1112

9. Prod'homme M, Rieu I, Balage M, Dardevet D, Grizard J (2004) Insulin and amino acids both strongly participate to the regulation of protein metabolism. Curr Opin Clin Nutr Metab Care 7:71-77

10. Sacchi S (2013) D-Serine metabolism: new insights into the modulation of D-amino acid oxidase activity. Biochem Soc Trans 41:1551-1556 
11. Tabe Y, Lorenzi PL, Konopleva M (2019) Amino acid metabolism in hematologic malignancies and the era of targeted therapy. Blood 134:1014-1023

12. Yoshii T, Kuji N, Komatsu S, Iwahashi K, Tanak Y, Yoshida H, Wada A, Yoshimura Y (2005) Fine resolution of human sperm nucleoproteins by two-dimensional electrophoresis. Mol Hum Reprod 11:677-681

13. Sato T, Ohgami S, Kaneniwa M (2015) Differences in compositions of free amino acids, nucleotiderelated compounds, and fatty acids between sexes of the coconut crab Birgus latro in Okinawa, Southwest Japan. Fish Sci 81:569-579

14. Boguenet M, Bocca C, Bouet PE, Serri O, Chupin S, May-Panloup P (2020) Metabolomic signature of the seminal plasma in men with severe oligoasthenospermia. Androl 8:1859-1866

15. Kimura K, Cuvier O, Hirano T (2001) Chromosome condensation by a human condensin complex in Xenopus egg extract. J Biol Chem 276:5417-5420

16. Lum KK, Kim J, Lei XG (2013) Dual potential of microalgae as a sustainable biofuel feedstock and animal feed. J Anim Sci Biotechnol 4:53

17. Shah AJ, Crespi F, Heidbreder C (2002) Amino acid neurotransmitters: separation approaches and diagnostic value. J Chromatogr B Anal Technol Biomed Life Sci 781:151-163

18. Huo TG, Chang B, Zhang YH, Chen ZX, Li WK, Jiang H (2012) Alteration of amino acid neurotransmitters in brain tissues of immature rats treated with realgar. J Pharm Biomed Anal $57: 120-124$

19. Zhang H, Wang YR, Li J, Lu J (2018) Biosynthetic energy cost for amino acids decreases in cancer evolution. Nat Commun 9:4124

20. Shimomura Y, Kitaura Y (2018) Physiological and pathological roles of branched-chain amino acids in the regulation of protein and energy metabolism and neurological functions. Pharmacol Res 133:215-217

21. Aquilani R, Viglio S, ladarola P, Guarnaschelli C, Arrigoni N, Fugazza G, Catapano M, Boschi F, Pastoris $O$ (2000) Peripheral plasma amino acid abnormalities in rehabilitation patients with severe brain injury. Arch Phys Med Rehabil 81:176-181

22. Kreft M, Bak LK, Waagepetersen HS, Schousboe A (2012) Aspects of astrocyte energy metabolism, amino acid neurotransmitter homoeostasis and metabolic compartmentation. ASN Neuro 4:e00086

23. a) McGrath NA, Andersen KA, Davis AK, Raines RT (2015) Diazo compounds for the bioreversible esterification of proteins. Chem Sci 6: 752-755. b) Zhang X, Wang JH, Tan D, Li Q, Lei X(2018) Carboxylate-selective chemical crosslinkers for mass spectrometric analysis of protein structures. Anal Chem 90: 1195-1201.

24. Martín-Gago P, Fansa EK, Winzker M, Murarka S, Janning P, Schultz-Fademrecht $C$, Waldmann H (2017) Covalent protein labeling at glutamic acids. Cell Chem Biol 24: 589-597.e5

25. Ma N, Hu J, Liu W, Huang M, Zhang Z (2020) 2H-Azirine-based Reagents for Chemoselective Bioconjugation at Carboxyl Residues inside. Live Cell 4: 1-8. 
26. Zhang C, Cui HY, Cai JR, Duan YQ, Liu Y (2015) Development of Fluorescence Sensing Material Based on CdSe/ZnS Quantum Dots and Molecularly Imprinted Polymer for the Detection of Carbaryl in Rice and Chinese Cabbage. J Agric Food Chem 63:4966-4972

27. Pa WX, Zhao JW, Chen QS (2015) Fabricating Upconversion Fluorescent Probes for Rapidly Sensing Foodborne Pathogens. J Agric Food Chem 63:8068-8074

28. Zhou T, Ji L, Luo YF, Xu J, Zhu TF (2016) Multifunctional nanocomposite based on halloysite nanotubes for efficient luminescent bioimaging and magnetic resonance imaging. Int $\mathrm{J}$ Nanomed 11:4765-4776

29. Wang L, Yu DL, Dai R, Fu D, Li WZ, Ma K (2019) PEGylated doxorubicin cloaked nano-graphene oxide for dual-responsive photochemical therapy. Int J Pharm 557:66-73

30. Yang R, Mu WY, Chen QY (2019) Urazole-Au Nanocluster as a Novel Fluorescence Probe for Curcumin Determination and Mitochondria Imaging. Food Anal Methods 12:1805-1812

31. Li WT, Chen SY, Shuang CD, Li AM (2020) Feasibility study for the analysis of coconut water using fluorescence spectroscopy coupled with PARAFAC and SVM methods. Br Food J 122:3203-3212

32. Wan JY, Yao HG, Zhang CF, Wang CZ, Yuan CS (2018) Red American ginseng enhances the effect of fluorouracil on human colon cancer cells via both paraptosis and apoptosis pathways. J Appl Biomed 16:311-319

33. Deng R, Shi L, Zhu W, Wang M, Guan X, Yang DL, Shen B (2020) Pharmacokinetics-based Dose Management of 5-Fluorouracil Clinical Research in Advanced Colorectal Cancer Treatment. Mini-Rev Med Chem 20:161-167

34. Wang CZ, Hou LF, Wan JY, Chen LN, Zhang QH, Liu Z, Sava-Segal C, Yuan CS (2020) Ginseng berry polysaccharides on inflammation-associated colon cancer: inhibiting T-cell differentiation, promoting apoptosis, and enhancing the effects of 5-fluorouracil. J Ginseng Res 44:282-290

35. Lin H, Man ZX, Kang WC, Guan BB, Xue ZL (2018) A novel colorimetric sensor array based on borondipyrromethene dyes for monitoring the storage time of rice. Food Chem 268:300-306

\section{Figures}




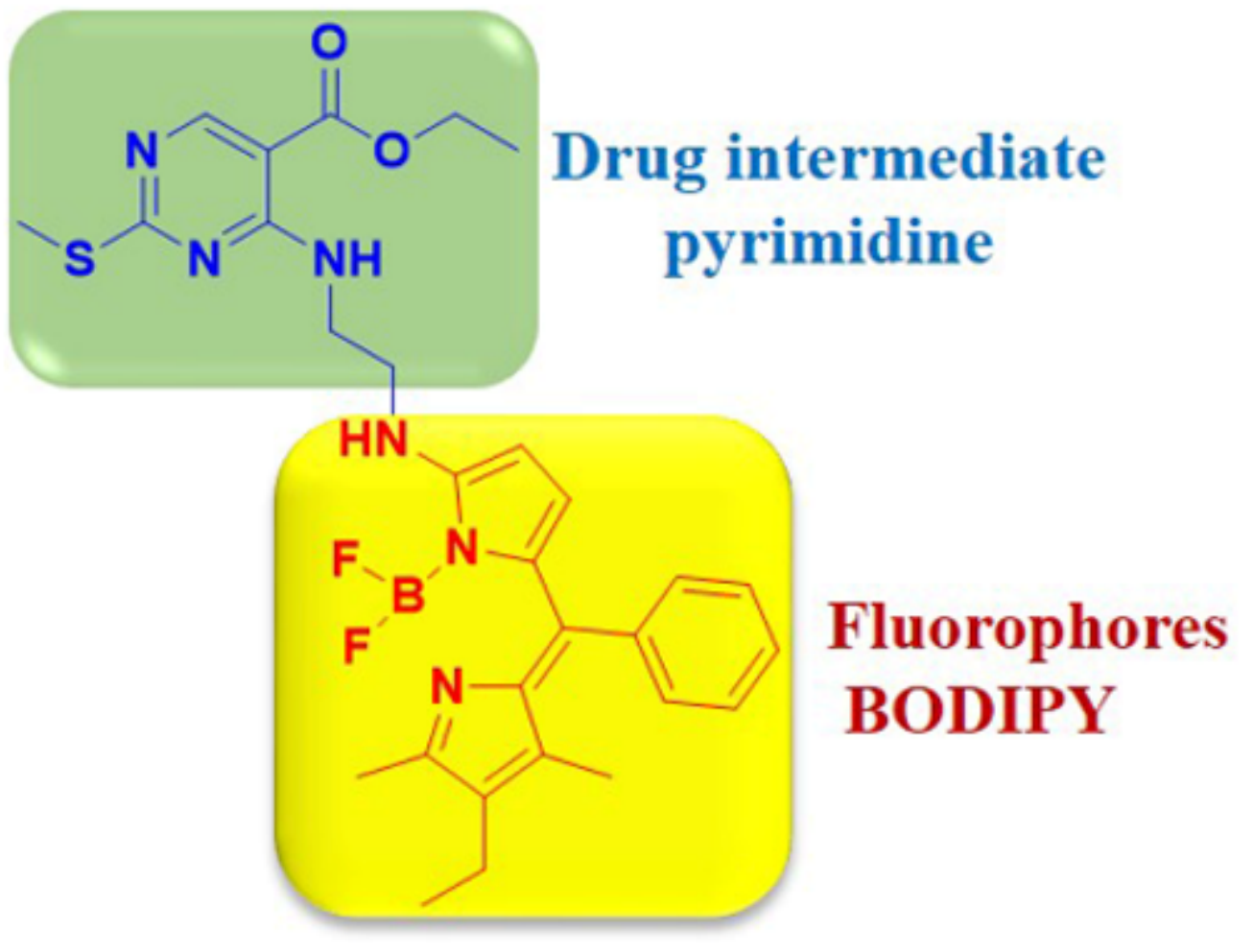

Figure 1

Structure of PyBODIPY probe. 

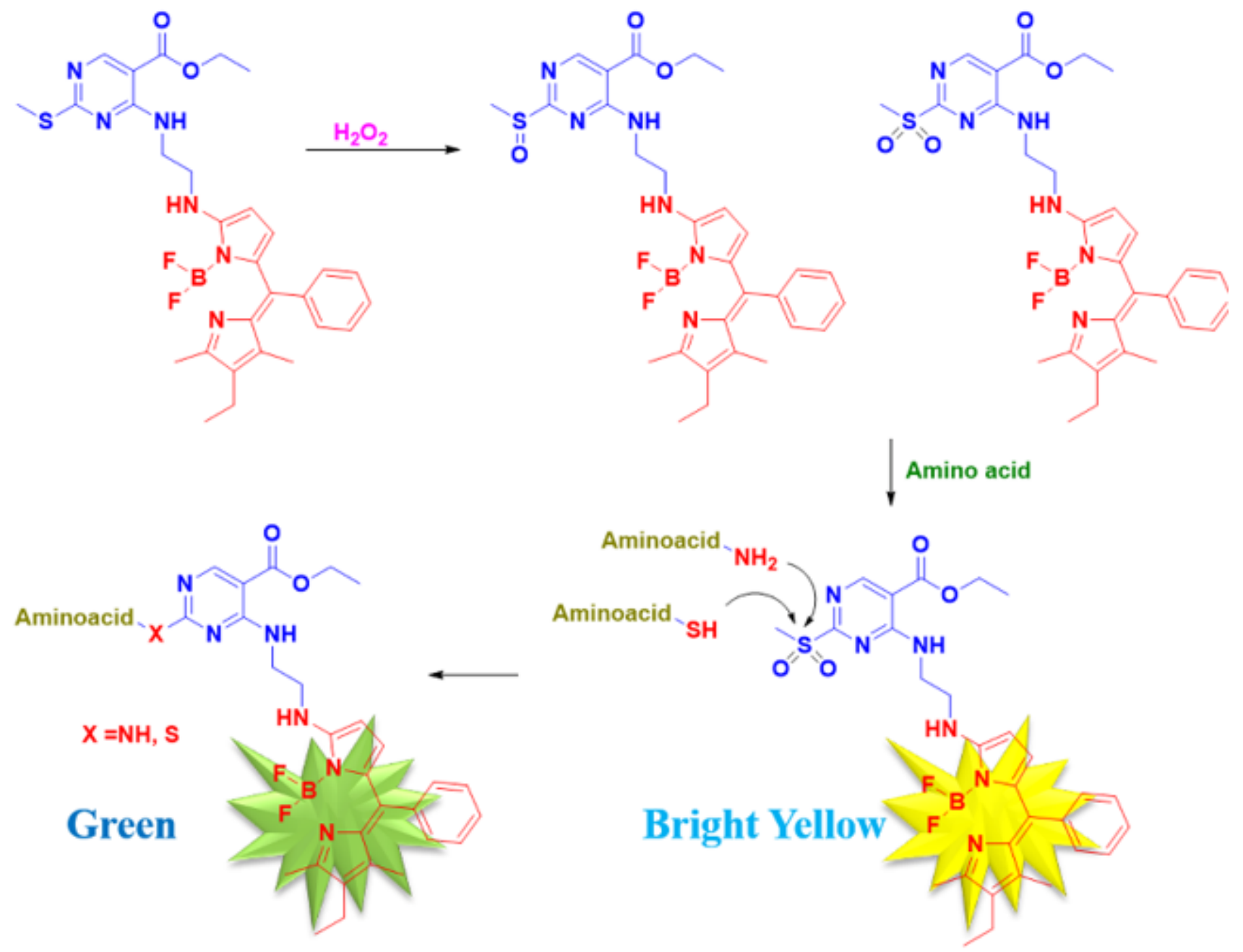

Figure 2

Mechanism of different amino acid identifications. 

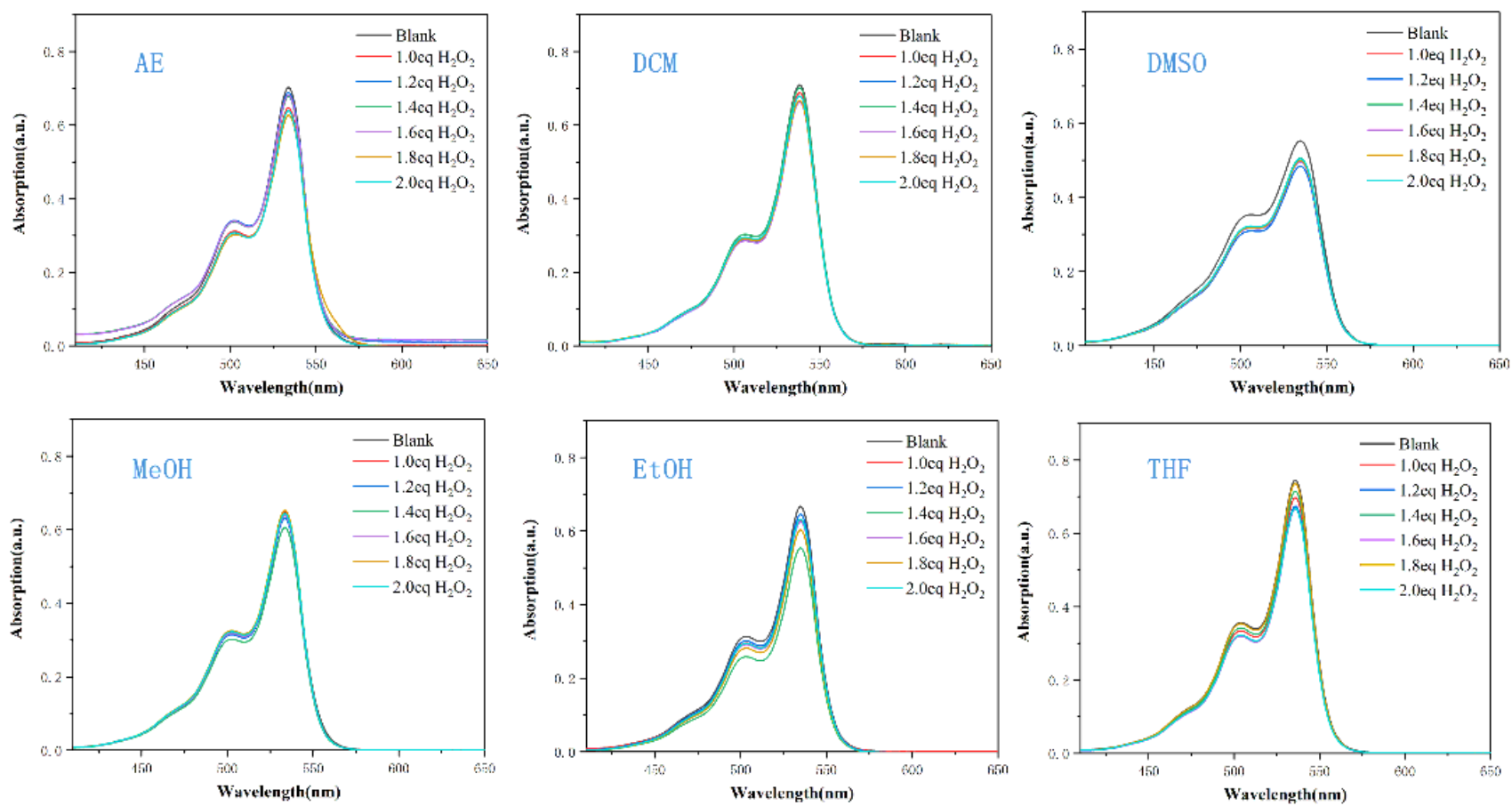

\section{Figure 3}

\section{UV spectrum of different equivalents hydrogen peroxide and PyBODIPY.}
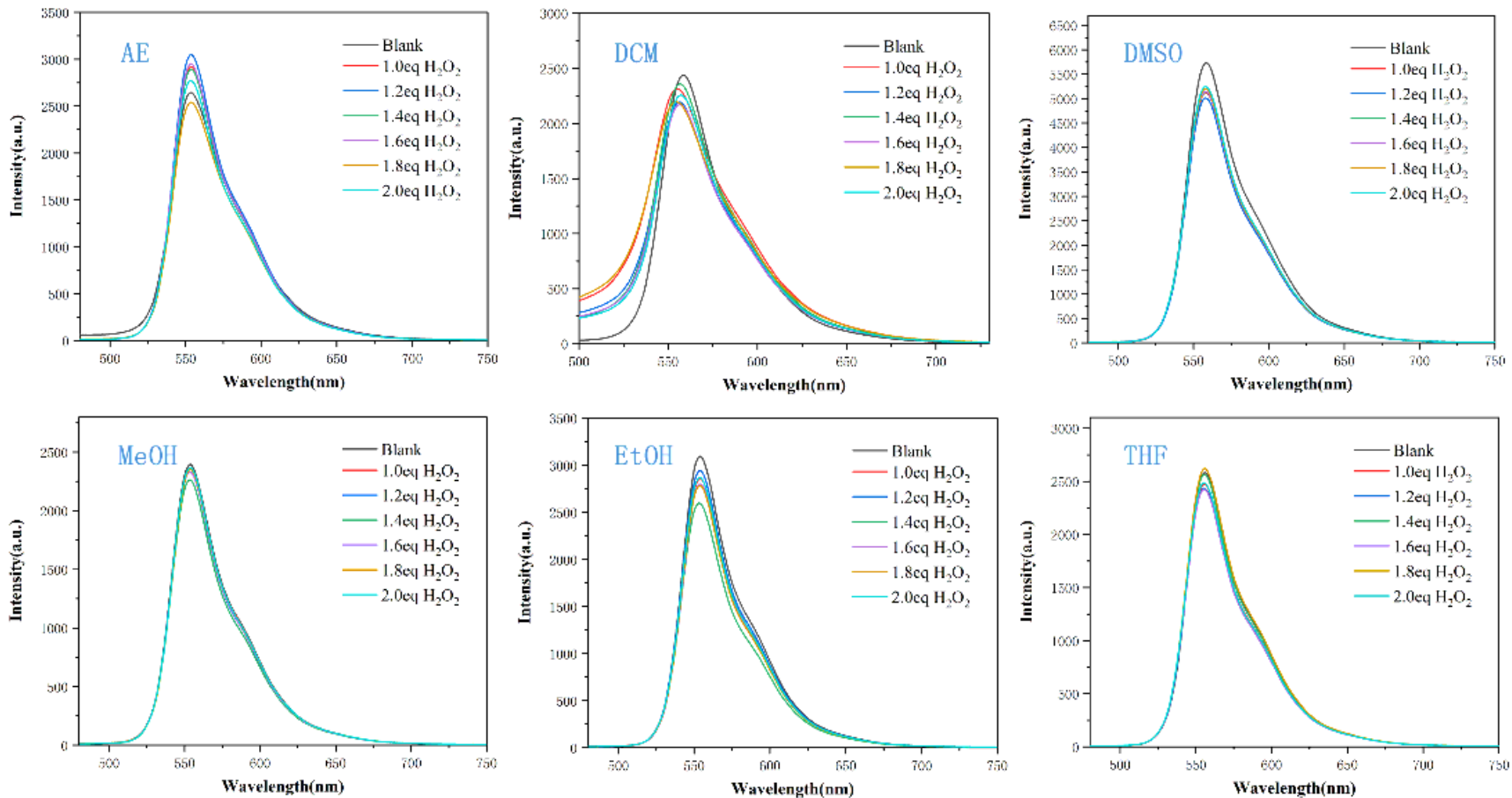
Figure 4

Fluorescence spectrum of different equivalents hydrogen peroxide and PyBODIPY.
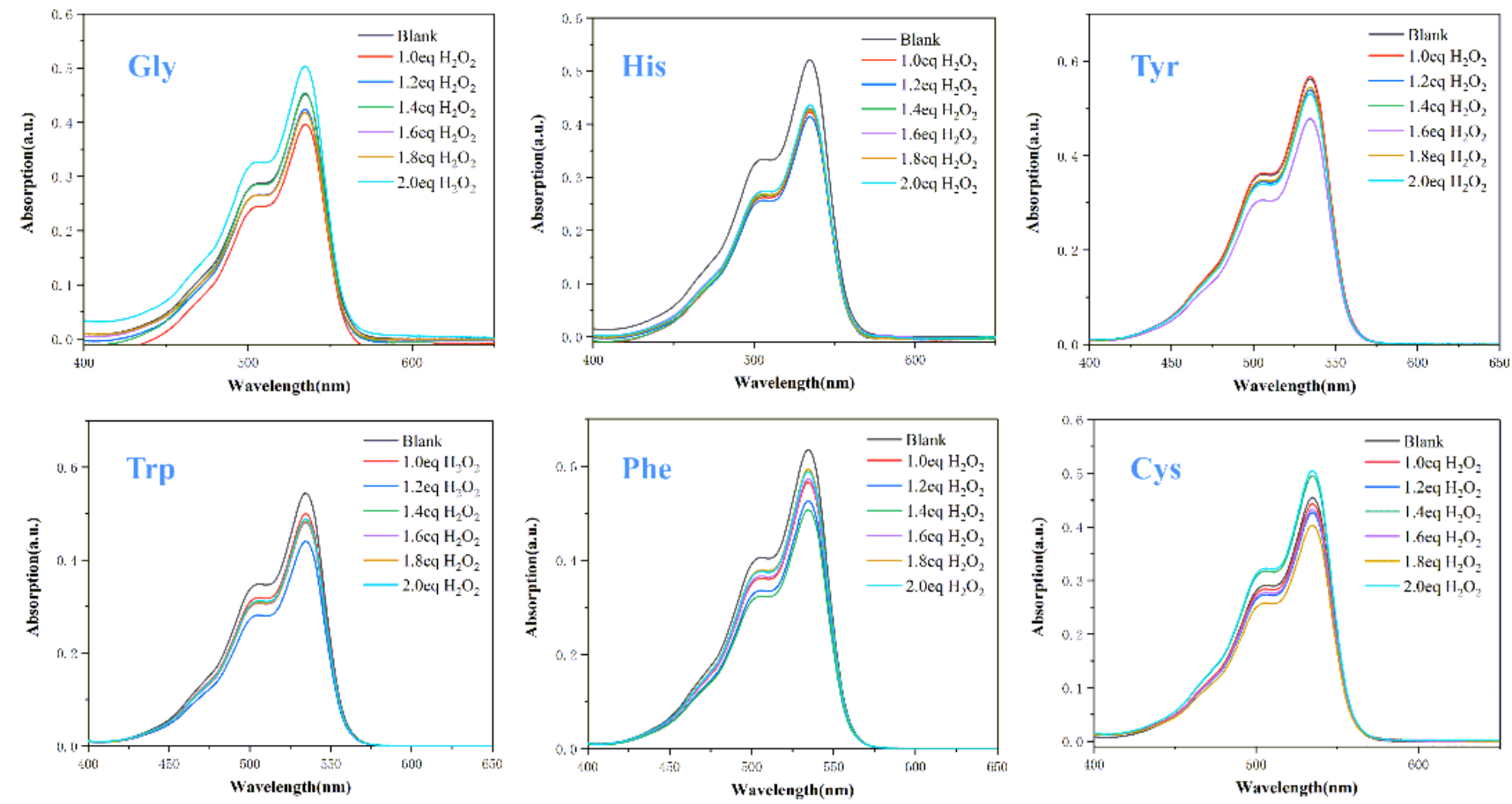

\section{Figure 5}

UV spectrum of different equivalents hydrogen peroxide, PyBODIPY and different amino acid. 

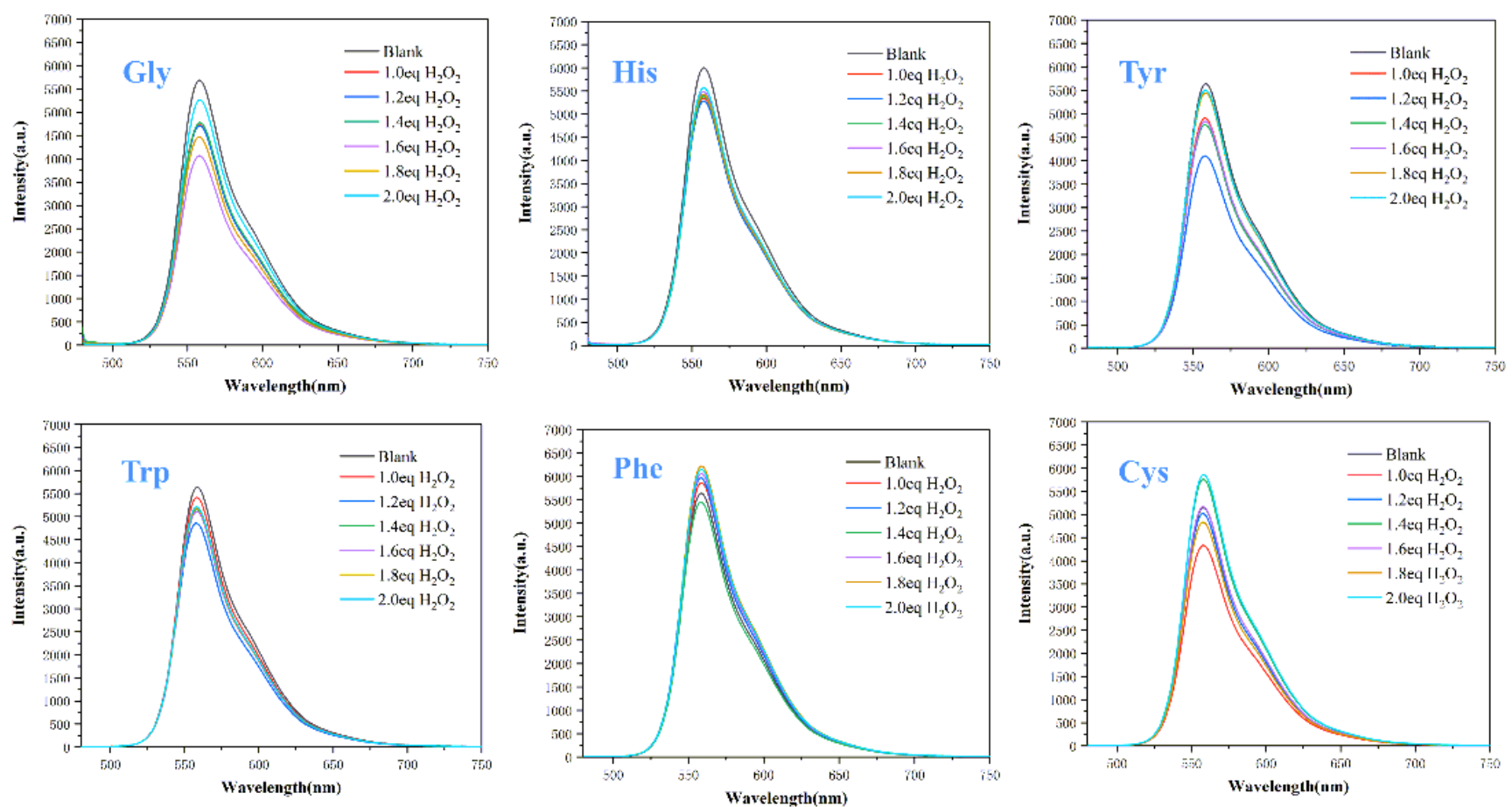

Figure 6

Fluorescence spectrum of different equivalents hydrogen peroxide, PyBODIPY and different amino acid. 


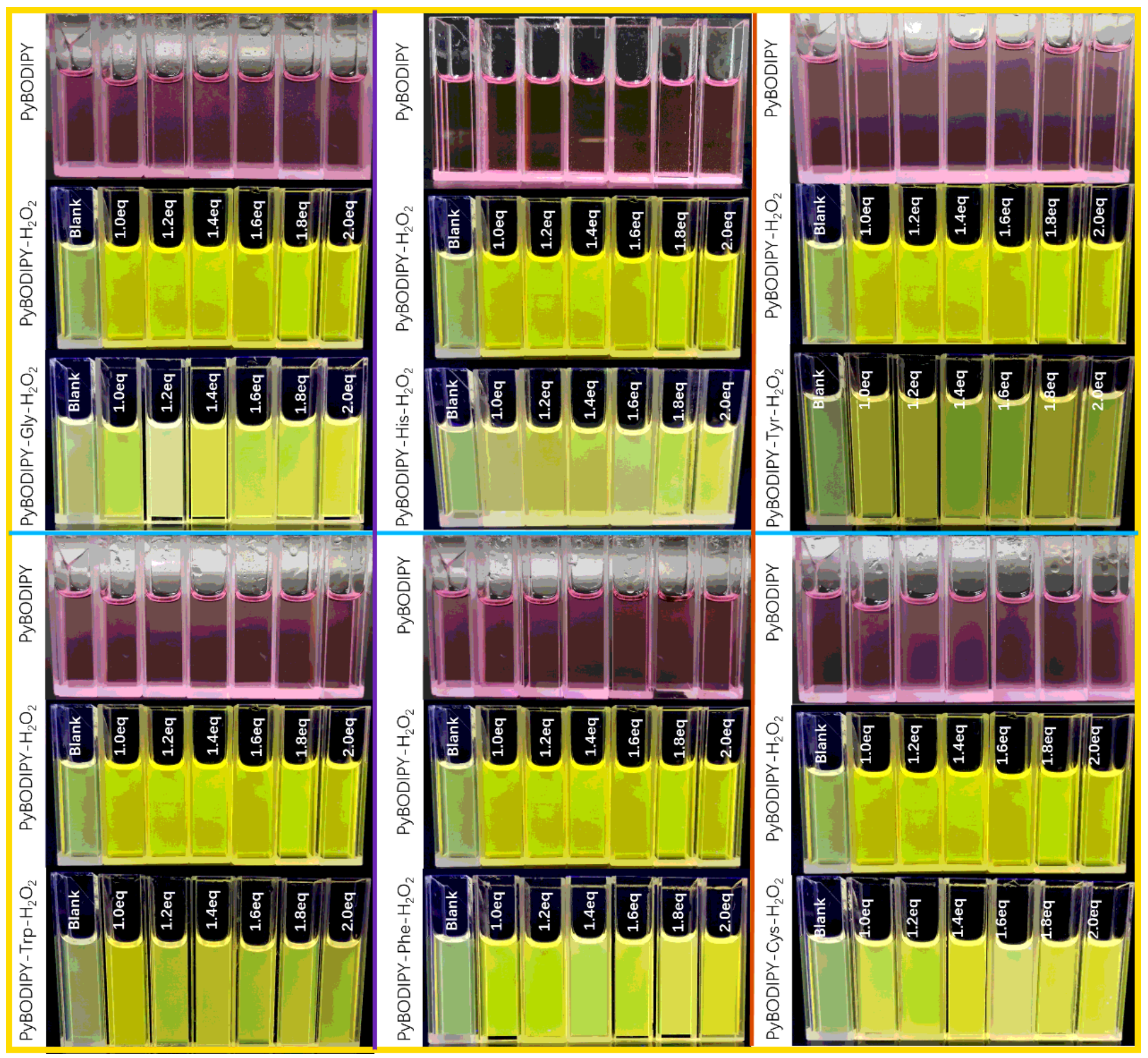

Figure 7

Changes in response to PyBODIPY and different amino acids.

\section{Supplementary Files}

This is a list of supplementary files associated with this preprint. Click to download.

- Scheme1.png

- GraphicalAbstract.png 